\title{
The effect of knowledge based view on sustainable competitive advantage
}

\author{
Fatemeh Rezaee $^{\mathrm{a}^{*}}$ and Mostafa Jafari ${ }^{\mathrm{b}}$
}

${ }^{a}$ Master student, Department of Industrial Engineering, Iran University of Science and Technology, Tehran, Iran ${ }^{b}$ Faculty member, Department of Industrial Engineering, Iran University of Science and Technology, Tehran, Iran

\begin{tabular}{l}
\hline C H R O N I C L E \\
\hline Article history: \\
Received July 5, 2015 \\
Received in revised format \\
August 162015 \\
Accepted January 102016 \\
Available online \\
January 112016 \\
\hline Keywords: \\
Knowledge based view \\
Sustainability capability \\
advantage \\
Structural equation modeling \\
Banking industry
\end{tabular}
A B S T R A C T

\begin{abstract}
This study investigates the quantitative relationship between knowledge based view (i.e. empowering employees, promoting confidence, coding rules) and sustainability competitive advantage (i.e. market, customer, financial) within the banking industry of Iran. A valid research instrument was utilized to conduct a survey of 150 top- and middle-level managers from Mellat bank of Iran. With a response rate of 81.3 percent, 122 questionnaires are returned; the number of valid and usable questionnaires was 101. In order to determine validity of questionnaire, the content validity was used and Cronbach's alpha was used to determine the reliability of the questionnaire (KBV questionnaire 0.886 , SCA questionnaire 0.843 ). Utilizing the structural equation modeling, and after a series of exploratory and confirmatory factor analyses, it was found that KBV had the greatest effect on the market centered SCA, while it had the least influence on the customer centered.
\end{abstract}

\section{Introduction}

In the present turbulent environment, organizations have shifted from contemporary approaches of strategy to the internal resources of the organizations to reach the SCA. Central to the topic of the resource based view is the role of organizations in developing valuable and rare resource and capabilities, which cannot be easily inimitable and it is not substitutable. In this perspective, knowledge is considered a key resource, as many scholars and practitioners have focused on that. Its proponents argue that because knowledge based resources are usually difficult to imitate and socially complex, heterogeneous knowledge bases and capabilities among firms are the major determinants of sustained competitive advantage and superior corporate performance. So the following questions may arise: whether KBV influences SCA of organization directly? What are the key factors that would be affected by resources and capabilities of KBV which would result in organization' SCA? According to knowledge related literatures, this paper argues that KBV not only has the positive relationships with financial performance directly but also influences market and costumer performance which are in turn

* Corresponding author. Tel: 98-913-1861455

E-mail address: fh_rezaee@ind.iust.ac.ir/fh_rezaee@yahoo.com (F. Rezaee) 
associated with overall performance of organization. This study aims to explore the relationships between KBV and SCA of organization from an empirical investigation of the Banking Industry Performance of Iran. The paper is organized into five sections including Section 1. Section 2 presents the literature review of this study. Section 3 describes the research methodology, operational measures of variables, and statistical analyses. Section 4 describes the hypotheses testing. Finally, Section 5 presents the conclusions of the study.

\section{Literature Review}

In the era of knowledge based view, resources and competencies related with knowledge are the crucial factors for organizations to survive in dynamic and competitive environment. In other words, one of the critical resources in the resource based view is knowledge that because of its importance should be studied in a unique and separate article. Having accepted the importance of knowledge, it is necessary to define knowledge capabilities for any organizations. Emphasis is placed on knowledge from a strategic point of view, rather than only from a scientific perspective. It is widely recognized that knowledge is an essential strategic resource for an organization to retain sustainable competitive advantage. Knowledge has the potential to contribute to the organization's value by increasing its capability to respond to new and unusual situations. In attempting to achieve this aim, this article is aimed at proposing KBV with regard to the progression of knowledge management strategy in an organization; the following aspects are given prominence: empowering employees, promoting confidence, coding rules.

\subsection{Knowledge Based View}

In the present postindustrial society, knowledge has become a key resource of the organization to reach the SCA. However, organizations face limitless challenges in managing knowledge. These challenges are occurring because traditionally managers have worked with physical and tangible resources and thus implementation of the intangible resources like knowledge is hardness for them (Nonaka \& Takeuchi, 1995; Prahalad \& Hamel, 1990). Drucker (1993) predicted that competitive advantage in the future would be determined by knowledge resources, or what is known as knowledge workers. Consequently, both scholars and practitioners have increasingly paid great attention on an organization's ability to identify, capture, create, share or accumulate knowledge (Jang et al., 2002; Kogut \& Zander, 1996; Michailova \& Husted, 2003; Nonaka \& Takeuchi, 1995). Later, many pointed out that knowledge would replace equipment, capital, materials and labor to become the most important element in production. However, there is no agreement among researchers about the definition of knowledge. Davenport et al. (1998) defined knowledge as "information combined with experience, context, interpretation and reflection that is ready to apply to decisions and actions." Marakas (1999) agreed that knowledge is an organized combination of ideas, rules, procedures, and information. Zeleny's (2005) argument knowledge encompasses human feedback and collaborative learning. Knowledge can fall into different scopes depending on the organizational context or area under that, for example, technical knowledge, customer related knowledge, and product related knowledge or managerial knowledge (Barchan, 1998; Rowley, 2005; Tanriverdi, 2005, Massey et al., 2002; Collinson, 1999; Akroush, 2010). Particularly in organizations how knowledge is managed is very important. Knowledge management is thus a process of facilitating knowledge related activities, such as creation, capture, transformation, and use of knowledge. Knowledge management strategy has been argued to contribute to the generation of various organizational capabilities such as innovation which is vital to an organization's SCA. Macintosh (1998) stated knowledge management can be defined as a discipline that involves the recognition and analysis of obtainable and required knowledge assets and processes and control of actions to develop them so as to fulfill organizational objectives. The management process includes a range of activities ranging from learning, collaboration, and experimentation to integration of diverse sets of tasks and implementation of powerful information systems, such as Internets, intranets, and extranets. Knowledge management strategy has been argued to contribute to the generation of various organizational capabilities such as innovation which is vital 
to an organization's SCA (Kogut \& Zander, 1996; Jafari \& Rezaee, 2014). Bhatt (2000) argues that a part of knowledge is individual and the other part of knowledge is organizational. One of the important tasks for management is to facilitate the process of interactions between employees and make them sensitive toward environmental stimuli so that their individual knowledge is amplified and internalized to contribute to the organizational knowledge base (Nonaka, 1994). So the goal for management is to encourage employees to continually refresh their knowledge base by interacting with those who possess work-specific skills and expertise. Bhatt (2002) stated in the four steps how an organization can manage different kinds of knowledge, which was defined as the process of creating, capturing, distributing, and using knowledge for the accomplishment of a task. In the first step, management should prepare broad guidelines under which employees can apply their discretion. Also, they should empower and enable their employees to face routine work processes and problems and also their quick understanding and solving through work related training. The employees should have training to have courtesy towards customers, and responsiveness to customers' demands. In the second step, the goal of management should be on motivating and the nurture of experts' skills. Management should determine the ways through which it can balance the exploitation of experts' knowledge and the desires of experts. In the third step, the process of multiple interpretations on knowledge is important as it allows individuals to revise, reshape, or modify their belief systems in relation to others and conducive to enhancing the richness of the organizational knowledge base. In the fourth step, rules and procedures are clearly marked. There is far less ambiguity in understanding and interpreting those. Therefore, management should implement the four steps to manage and to enhance employees' knowledge through individual interactions. According to the views of Bath (2002), a questionnaire was drawn up and its results were analyzed using exploratory factor analysis. Finally, three categories were obtained that were called empowering employees, promoting confidence and motivation of employees, and coding rules.

\subsection{Competitive Advantage}

Although there are many different viewpoints among the discussed theories to reach SCA, they are similar in one way which their aim is to maximize the organizational competitive advantage and improve the organization's position among their competitors. It has been a long disputation about how organizations could reach to sustainable competitive advantage. Also many experts have revealed their opinions for such a matter such as Porter who believed that cheap labor and natural resources are not enough for good economy requirements (porter 1985 cited by Andersen, 2013). A competitive advantage is the ability which is obtained through resources and attributes that helps a firm perform at a higher level than the other competitors in the same industry or market. When a firm has reached a competitive advantage, prevented imitation by competitors, resisting erosion by competitor behavior and achieving sustainable competitive advantage is considered as an obvious result. However preventing imitation is not permanent; the firm should make any effort to delay this occurrence to gain the maximum benefit from its competitive advantage (Reed \& Defillippi, 1990; Pearce \& Robinson, 2000; Christensen, 2001; Chunxia, 2012, Rezaee \& Jafari, 2015). Barney (2000) argued that a firm has a competitive advantage when it applies a value creating strategy while any current or potential competitors are deprived to implement the strategy simultaneously and they are also not capable of replicating that. A competitive advantage of firm is assumed as a sustainable paradigm as long as competitors are unable to duplicate it; in this sense it would not last if they become aware of how they can imitate it. It has to be noted that industry type has a significant effect on a period of calendar time that a firm enjoys a concept of sustained competitive advantage so that sustainability lasts longer in high-tech industry than other Industries.

In 1990, Prahalad and Hamel reported that Western and Japanese companies could conquest competitors to standardize product cost and quality. Although these competencies could be considered as an option to a firm but nowadays they are not dramatically emphasized as the only sources to gain a competitive advantage. In other words, cost and quality can be as an enabler to a firm to overcome competitors but they are not enough. Surveys were conducted by Prahalad and Hamel (1990) to identify why a service quality of Pakistan telecom cannot result to a firm competitive advantage. The study 
demonstrated that the telecom industry has a low rating on personal attention to customers and understanding their needs. The question of what leads to a sustainable competitive advantage is not only about today's economic crisis, but also is a question that each company should follow to find a fairly feasible answer (Oliver, 2000).

According to Reed and Defillippi (1990) the sources of competitive advantage are as numerous as firm activities. A research including a study of 59 articles in 8 fields (strategic management, strategic management of marketing, marketing management, information technology, knowledge management, resources-based theory, entrepreneurship, and human resource management) demonstrated that among Porter's triple strategies, the strategy of differentiation has captured highest attention (Hamidizadeh \& Taheri, 2013). A successful company should focus on its core competence and invests in development of activities creating value and reaches core competence that is the source of comtetive advantage. Core competence is considered as a fundamental concept for competitive strategy in a highly competitive market which is identified as knowledge set helping a company to perform in a different way from competitors and results to a competitive advantage. The core competence concept has been implemented to an organization identifying and efficiently utilizing its strength. Gupta et al., (2009) further argued that core competence is a collection comprised of communication, involvement and a deep commitment across organizational boundaries. Ljungquist (2008) demonstrated that core competence has been emerged to justify business diversity at large companies and provide support for some internal processes including product development. In 1990, Prahalad and Hamel introduced companies' ability as a real source of competitive advantage empowering business to overcome competitors through rapidly changing environment by consolidating technologies and production skills. It has to be emphasized that a firm could reach sustainable competitive advantage if it enjoys having rare, unique and none-replaceable resources. Gupta et al. (2009) point out these resources are not generally capable of creating a competitive advantage which is in higher level than others. A company needs to answer the questions of how it can use available sources and how to create new resources and finds a new approach to develop a new type of product and services and finally how these resources which are considered as a special form of final products and services can create a competitive advantage to a firm and contribute to create the firm's value. Surveys conducted by Holliday (2001) show sources of firm's competitive advantage should be supported by human factors. According to his argument, factors including organizational classes, knowledge management, leadership styles, and work teams and so on have a more considerable impact on effective use of the sources. Management is a most effective component of a companies' competitive advantage that should not be ignored (White \& Moraschinelli, 2009). In other words there is not any other entity with such an important effect and influence to reach competitive advantage (Burns, 2008). Trung (2014) believed that a strategic position of managers is necessary to obtain sustainable competitive advantage and improve companies' position among competitors.

\subsubsection{Ensuring of competitive advantage}

In some cases it is impossible for competitors to imitate, however, is quite rare. Imitation is one of the most challenging issues for an organization to sustain a competitive advantage. Therefore a firm should invest on raising a barrier to imitation in order to ensure sustainability of competitive advantage. Although it is inevitable that a competitive advantage cannot be quite sustainable and finally competitors can find a way to realize how they can imitate the strategy using by the firm (Christensen, 2001). However there is no insuperable barrier to imitation, an organization has to prolong the competitive advantage with emphasis on two proposed strategies as follow. First, organizations should make their effort to not let competitors comprehend the foundation of their strategy and realize how they create the competitive advantage. Second, strategies have to use an array of activities instead of using a single activity. This means matching an array of interlocked activity and making an ambiguous strategy to implement which is harder for the competitors to duplicate. As this approach reduces the probability of competitors' imitation, it may ensure competitive advantage. 


\subsubsection{Sustainable competitive advantage}

It has to be acknowledged that reaching a competitive advantage has been a matter of significance for an organization since before and much attention has been paid to this issue by a wide range of experts and specialists. It may be said the most important subject in a competitive advantage concept is the question of what are the possible signs of a competitive advantage; in other words what are the measures showing that a company has reached a competitive advantage. According to the literature review and experts views on the subject, the mentioned measures have been classified into three categories comprised of market, finance and customer and then have been fairly surveyed more. A sustained competitive advantage is obtained through unique values which are creating a strategy that any other current or potential competitor is unable to imitate or imply it simultaneously and finally the using strategy cannot be duplicated for long period of time.

\section{Customer}

A core competence which is defined as a skill enabling an organization to create a fundamental value and leads to customer loyalty should result to customer perceived value. Studies show that customer loyalty and customer attention are two challenging concepts that all organizations encounter. It is exactly clear that loyal customers can raise sales and customer share and reduce costs and higher prices (Alrubaiee \& Alnazer, 2010). As a result, our study seeks to address two critical dimension of competitive advantage with focus on customers, including flexibility and responsiveness. Flexibility refers to organization capabilities to provide a superior customer value (Johnson et al., 2008) and responsiveness is defined as an organization ability to respond fast to their customers' wants and needs (Carlos et al., 2010). A competitive advantage can be obtained through meeting organizational goals and customer needs in a highly competitive environment (Evans et al., 2006). Therefor organizations should fight against each other for capturing customer attention and making a loyal customer. In other words, a competitive advantage is reached when customer needs and wants are met more effective and efficient than competitors for a long time by a company, however their competitors make attempt to duplicate, reproduce and even surpass the competitive advantage.

\section{Market}

In 2010 a study conducted by Li and Zhou (2010) to investigate how market orientation and managerial tie can impact competitive advantage. This research showed that one of the most important dimensions of a firm's competitive advantage is institutional advantage which means an organization's superiority in obtaining rare sources and institutional support. In this context it is stated that brands and corporate images have a significant impact on sustained competitive advantage required for a highly competitive environment (Seetharaman et al., 2001; Amini, 2012).

\section{Finance}

Reaching a competitive advantage results to a position for a company due to which it can achieve and sustain above average profitability for some years (Jones \& Hill, 2013). It has to be noted that a profit is gained through sales incomes results from customer purchase (Rijamampianina \& Abratt, 2003; Thompson et al., 2012).

\section{Research model and hypotheses}

The search framework generated in this study is illustrated in Fig. 1. This framework briefly proposes that the three different items of KBV in the banking industry will enhance its SCA, which will then improve market, customer and financial performances. In the other hands, this paper aims to investigate the underlying influencing mechanism between KBV and SCA in the banking industry. It examines what types of components are most crucial to be converted into competitive advantage through $\mathrm{KBV}$, 
describes and understands factors of SCA and also determines relationship between KBV and SCA in the banking industry of Iran. So this paper proposes three following hypotheses.

Hypothesis 1 . Knowledge based view (KBV) is positively associated with Market centre sustainable competitive advantage (MSCA).

Hypothesis 2 . Knowledge based view (KBV) is positively associated with customer centred sustainable competitive advantage (CSCA).

Hypothesis 3. Knowledge based view (KBV) is positively associated with financial centred sustainable competitive advantage (FSCA).

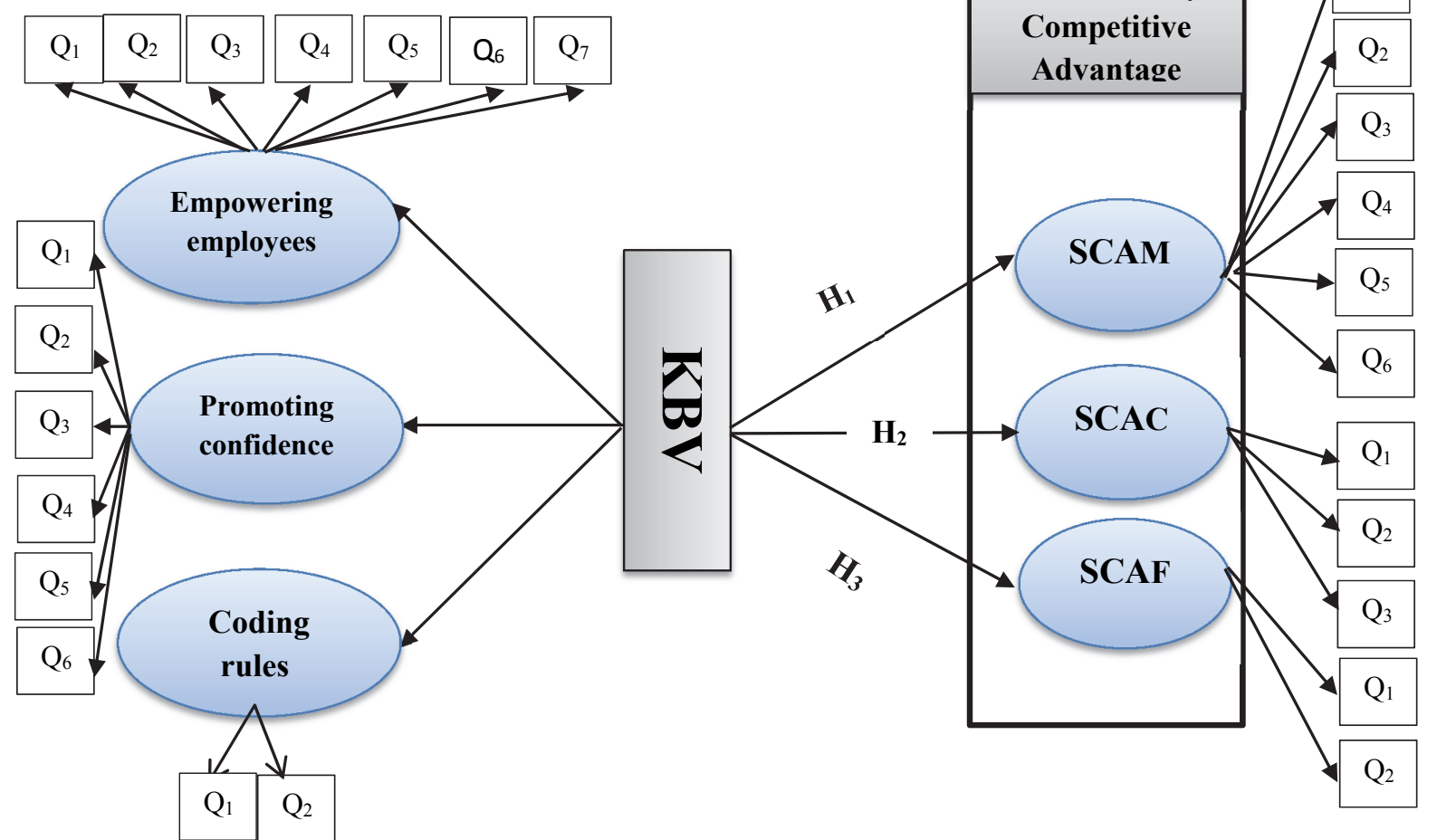

Fig. 1. Conceptual model between KBV and SCA

\subsection{Methodology}

The banking industry is a major part of Iran's economy. After the study of the performance statistics and information of Iranian banks, the interviews were conducted with expert academics in the banking industry and 50 of the deputy and directors of Iran banks. After all statistical studies and discussions, Mellat Bank Iran (MBI) was chosen as the case study because of the implement of appropriate strategies in maintains and enhance of its competitive advantage among other Iranian banks. The research has been shown MBI has reached to find the competitive advantage among their competitors in recent years. For this reason, this research attempts investigate this practical success in the context of scientific study. Following the investigations conducted different strategies lead to achieve these advantages. One of the most important strategies is the dynamic capability and its implementation in the Mellat bank. MBI has the considerable growth in the competition with rival, turned a suitable locale for research to examine the influence of DC on SCA in the banking industry. As an effort to ascertain the content validity of the survey questionnaire, a draft survey was pre-tested by both academicians (i.e. two Strategic Management Assistant Professor) and practitioners (i.e. ten managers' Bank). The participants were requested to evaluate the survey questionnaire on its wording, clarity and relevancy. Ultimately, the final version of questionnaire was distributed randomly to those who are in the 
executive or Senior Managers, specialists and consultants from the administration and improvement methods, marketing, strategy, risk management and operations manager department of MBI. The reason of choosing this group of professionals as the unit for analysis is because they are the most knowledgeable in terms of the research issues of the study.

From the total of 150 questionnaires circulated, 122 were returned with complete answers, which represent a response rate of $81.3 \%$. The number of valid and usable questionnaires was 101 . The Fig. 2 shows the company characteristics and the target respondents. The Fig. 2 shows that the majority of Respondents, 81.1 percent, are males that are consistent with the Iranian society which is still relatively a male dominated especially on the top management positions. The majority of managers are middleaged and well educated. This is consistent with the Iranian society that is described as Middle-aged and enjoys high levels of education in the bank department. Being well educated would greatly help MBI in building and accumulating DC to reach SCA now and in the future. Also, the Fig.2 shows that the majority of managers, 67 percent, is well experienced in this industry and has more than ten years of experience. This holds a strategic implication that indicates that MBI has relevant and sufficient business industry experience that is crucial for building and sustaining assets and capabilities as a source of competitive advantage for a long time. Finally, the Fig. 2 shows that 61.6 percent of managers have business education background which indicates there is reasonable recruitment process in the bank that focus on quality of people as one of their major assets to achieve a success. The part of measure is organized into two sections that present how to measure the dimension of each construct. It should be mentioned, in order to assess the precision and focuses of the respondents, some questions were designed negatively.

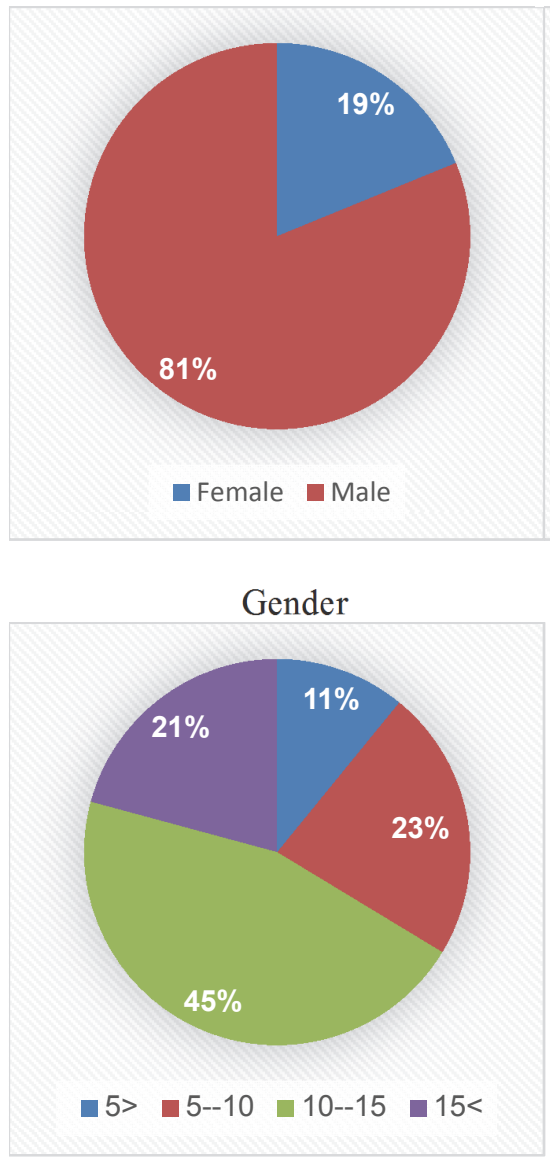

Job experience
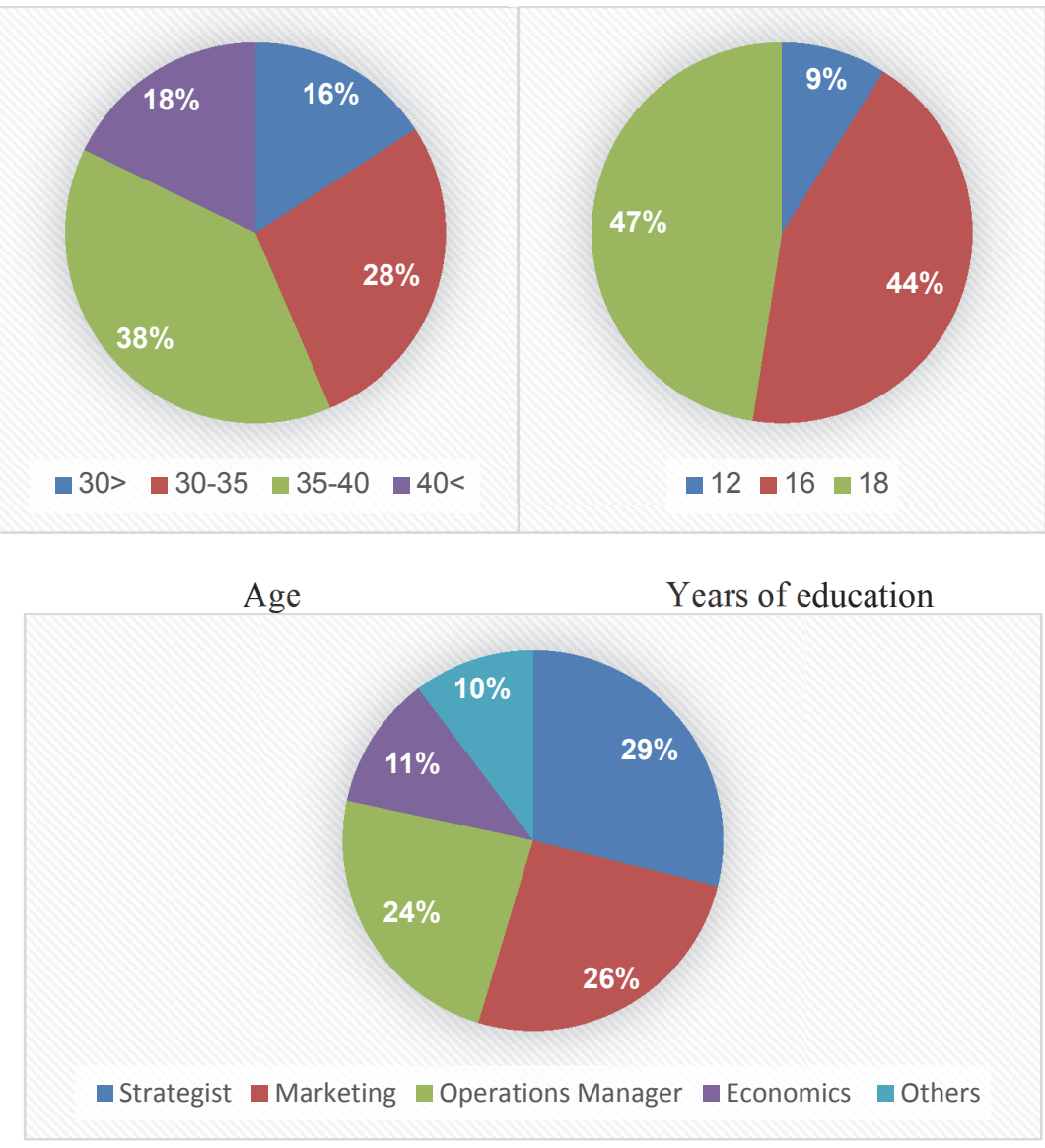

Educational background

Fig. 2. Personal characteristics of the participants 


\subsection{Measure of $K B V$}

Three knowledge based view dimensions including: empowering employees, promoting confidence, coding rules focus were evaluated in this study. These KBV dimensions were selected based on the studies carried out by Bhatt (2002). Each of these KBV practices was measured via a five-item, 5point Likert scale ranging from strongly disagree $=1$ to strongly agree $=5$.

\subsection{Measure of SCA}

The instrument of SCA has been used to assess SCA across various competitive advantage settings. Thus the three area of SCA were chosen to represent the SCA dimensions in the present study as a result. A review of the literature concerning the sustainable competitive advantage in service institutions such as banks found that most research assessed the construct of service institutions from the market, costumer and finance perspective. Each of these SCA practices was separately measured and analysis. In order to measure respondents' perception towards the SCA within bank, a 5-point Likert scale was developed $(1=$ strongly disagree; $5=$ strongly agree $)$.

\subsection{Statistical data analysis}

The data analysis was performed in fore steps: first is check of normality assumption, prior to the analysis of the data, the normality assumption is used in the data preparation stage. One of the main functions includes checking multivariate normality to determine if a data set is well modelled by a normal distribution. Second step is Factor Analysis consists of two parts, the first Kaiser-Meyer-Olkin (KMO) and Bartlett's Test and the other exploratory factor analysis. Statistical data analysis should always be asked questions such as: Is the strength of the relationship among variables large enough? Is it a good idea to proceed a factor analysis for the data? Factor Analysis can reply to these questions with KMO and Bartlett's Test. The Kaiser-Meyer-Olkin (KMO) measure of sampling adequacy tests whether the partial correlations among variables are small. The Kaiser-Meyer-Olkin measure of sampling adequacy is an index for comparing the magnitudes of the observed correlation coefficients to the magnitudes of the partial correlation coefficients. Another indicator of the strength of the relationship among variables is Bartlett's test of Sphericity. Bartlett's test of Sphericity tests whether the correlation matrix is an identity matrix, which would indicate that the factor model is appropriate. This test is used to test the null hypothesis that the variables in the population correlation matrix are uncorrelated. In order to separate the dimensions of each construct, Exploratory Factor Analysis (EFA) perform with Varimax rotation. Third, is to carry out the confirmatory factor analysis. A confirmatory factor analysis (CFA) is performed to evaluate the overall measurement model. In order to evaluate the validity of measurement model, convergent and discriminant validity were evaluated. Convergent validity, along with discriminant validity, is a subtype of construction validity. Convergent validity can be estimated using correlation coefficients. Convergent validity is concerned with the degree that the both assessments of constructs theoretically and actually should be related (Campbell 1959). A successful evaluation of convergent validity shows that a test of a concept is highly correlated with other tests designed to measure theoretically similar concepts. Finally, forth step is examining the hypotheses through SEM. From the methodological perspective, the hypotheses formulated were measured and tested using the SEM approach. This method proved to be far more superior to regression analysis. Firstly, while SEM approach supplies statistical competency and provides a definite method to deal with multiple relationships simultaneously, multiple regression analysis does not. Secondly, as SEM is capable of testing the relationships comprehensively, it has moved from exploratory factor analysis to confirmatory factor analysis. Thirdly, the unobserved concepts and the measurement error in the estimation process are also taken into the account with the use of the SEM practice (Kline, 2005). Given the many advantages of SEM, coupled with the support of many researchers stating that such an approach is a useful methodological assessment tool for many measurement models (Bollen, 1989), Therefore SEM was chosen to test the structural relationships between the four constructs of KBV, MSCA, CSCA, and FSCA. 


\subsection{Tests Results}

The KMO measures the sampling adequacy which should be greater than 0.5 for a satisfactory factor analysis to proceed. Looking at the Table 1 and Table 2, the KMO measures are 0.858 and 0.820 for KBV and SCA, respectively. Large values for the KMO measure indicate that a factor analysis of the variables is a good idea. From the same table, we can see that the Bartlett's test of Sphericity is significant. That is, its associated probability is less than 0.05 . In fact, it is actually 0.000 . It is small enough to reject the hypothesis. This means that the correlation matrix is not an identity matrix. It is concluded that the relationship among variables is strong. It is a good idea to proceed an exploratory factor analysis for the data.

In the course of the validation process, three items (3 items from SCA factors) were found to have unacceptably low factor loadings of less than 0.5 on their respective unobserved hypothetical or latent variable which were subsequently removed. The internal reliability is evaluated of scales by Cronbach's alpha $(\mathrm{C}-\alpha)$. The result has shown that the Cronbach's alpha value ranges between 0.765 to 0.953 for KBV factors, 0.844 for SCA of market entered, 0.777 SCA of customer centered and 0.717 for financial centered indicating the measurement of the variables are well above the acceptable threshold of 0.70 according to Nunnally and Bernstein (1994).

A convergent validity has been tested by assessing factor loadings which should be significant and exceed 0.5, composite reliabilities (CR) which should exceed 0.7 , and the average variance extracted (AVE) that should be more than 0.5 for all constructs (Fornell \& Larcker, 1981). In our model, all the factor loadings and composite reliabilities fall in the acceptable ranges and are significant at the 0.001 level. Factor loadings range from 0.52 to 0.98 and 0.52 to 0.94 , Composite reliabilities (CR) range from 0.762 to 0.922 and 0.703 to 0.851 , AVE ranges from 0.522 to 0.860 and 0.556 to 0.659 for KBV, SCA, respectively. The results show that our model meets the convergent validity criteria. Table 1 shows the means, SD, factor loading, AVE, CR and C- $\alpha$ of every constructs. Convergent validity can be established if two similar constructs correspond with one another, while discriminant validity applies to two dissimilar constructs that are easily differentiated. A successful evaluation of discriminant validity shows that a test of a concept is not highly correlated with other tests designed to measure theoretically different concepts (Kline, 2005). Fornell and Larcker's approach has been used to assess discriminant validity. In this approach, the AVE for each construct should be higher than the squared correlation between the construct and any of the other constructs. Table 3 indicates that the measurement model has satisfactory discriminant validity. In Table 4, diagonal elements in italics are the AVE and off-diagonal elements are the squared correlations between constructs. It is obvious that each diagonal element is higher than respective off-diagonal elements. Therefore, all constructs in the measurement model were judged as having adequate discriminant validity.

Fig. 1 exemplifies the proposed structural model showing the association between the five and three dimensions of KBV and SCA, respectively. To examine the model, conventional maximum likelihood estimation approaches were used. It is assessed the measurement model fit by evaluating: (1) absolute fit indices including observed normed $\chi^{2}\left(\chi^{2} / \mathrm{df}\right)$, goodness of fit index (GFI), adjusted goodness-of-fit index (AGFI) and adjusted goodness-of-fit index (AGFI); (2) Comparative fit indices including normed fit index (NFI), and comparative fit index (CFI); and (3) parsimonious fit indices including parsimony goodness-of-fit index (PGFI) and parsimony normed fit index (PNFI) and the root mean square error of approximation (RMSEA). The summary results of the structural equation modelling technique are shown in Table 5. Examples of the fundamental measures are the ratio of $\chi^{2}$ statistics to the degree of freedom (df), normed fit index (NFI), comparative fit index (CFI), goodness-of-fit index (GFI) and the root mean square error of approximation (RMSEA). Table 5 summarized the results of CFA models, all the model-fit indices are well above their common acceptable levels in which $\chi^{2} / \mathrm{df}$ was less than 3.0 and greater than 0.90 for GFI, AGFI, CFI and NFI as suggested by Bagozzi and Yi (1988), with RMSEA less than 0.08 according to Browne and Cudeck (1993), suggesting that the CFA models fit well. In their studies, Anderson and Gerbing (1988) suggest that values greater than 0.90 are desired 
for GFI, CFI, AGFI, and NFI while Browne and Cudeck (1993) required values less than 0.08 for RMSEA. Based on Table 5, the ratio of $\chi^{2}$ statistics to the degree of freedom for our model was 2.8. The value of the remaining fit indices include the GFI $=0.96$; $\mathrm{AGFI}=0.91 ; \mathrm{CFI}=0.94 ; \mathrm{NFI}=0.95$; and RMSEA $=0.072$ ). All the model-fit indices are well above their common acceptable levels, suggesting that the structural model fits well. It can be concluded that a goodness-of-fit exists for the measurement scale of market orientation. Therefore, we can conclude that the model fits the data well and thus is able to explain the research hypotheses.

Table 1

Results of CFA and internal reliability testing \& $\mathrm{K}-\mathrm{M}-\mathrm{O}$ measure

\begin{tabular}{|c|c|c|c|c|c|c|}
\hline Factor & Mean & SD & Loading & AVE & $\mathrm{CR}$ & $\mathrm{C}-\alpha$ \\
\hline Factor 1: (Empowering employees) & & & & 0.54 & 0.82 & 0.823 \\
\hline $\begin{array}{l}\text { has made it possible for employees to apply their individual experiences they } \\
\text { have had during their work }\end{array}$ & 3.65 & 0.888 & 0.77 & & & \\
\hline $\begin{array}{l}\text { has provided a condition in which responsible and aware employees may turn } \\
\text { their ideas into reality }\end{array}$ & 3.58 & 0.941 & 0.67 & & & \\
\hline $\begin{array}{l}\text { maintains that employee training which is related to employee performance, job } \\
\text { processes and professions is the most significant function of an organization }\end{array}$ & 3.64 & 0.916 & 0.75 & & & \\
\hline $\begin{array}{l}\text { has not provided appropriate trainings by which employees may realize the } \\
\text { business camouflaged reality }\end{array}$ & 3.53 & 0.819 & 0.74 & & & \\
\hline $\begin{array}{l}\text { try to revive and accomplish knowledge-based concepts by using knowledge-led } \\
\text { team }\end{array}$ & 3.46 & 0.954 & 0.98 & & & \\
\hline is becoming more empowered by holding scientific and knowledge-led meetings & 3.29 & 0.887 & 0.90 & & & \\
\hline $\begin{array}{l}\text { surveys problems and detects the best solution regarding employee commitment } \\
\text { by making participation }\end{array}$ & 3.38 & 0.906 & 0.73 & & & \\
\hline Factor 2: (promoting confidence and motivation of employees) & & & & 0.56 & 0.76 & 0.765 \\
\hline $\begin{array}{l}\text { has believed that employee behavior with customers is one of the evaluating } \\
\text { factors requiring for their competency }\end{array}$ & 3.53 & 0.819 & 0.88 & & & \\
\hline is able to fulfill expert needs and can encourage and reward them & 3.01 & 0.971 & 0.92 & & & \\
\hline the experts and qualified and smart people are not free for what they want to do & 3.28 & 0.932 & 0.73 & & & \\
\hline $\begin{array}{l}\text { has got balance between organizational rules and requirements, and employee } \\
\text { creativity and risk taking }\end{array}$ & 3.11 & 0.927 & 0.76 & & & \\
\hline holds discussion and brainstorm meetings to improve employee communications & 2.95 & 0.908 & 0.97 & & & \\
\hline $\begin{array}{l}\text { let's people revise what they think about each other by having knowledge-led } \\
\text { conferences }\end{array}$ & 3.23 & 0.914 & 0.84 & & & \\
\hline Factor 3: (coding rules) & & & & 0.61 & 0.83 & 0.953 \\
\hline clarifies rules and procedures to prevent employee multi-faceted understandings & 3.19 & 0.952 & 0.91 & & & \\
\hline $\begin{array}{l}\text { reviews all prescriptions throughout the entire organization as the environment } \\
\text { changes }\end{array}$ & 3.14 & 0.898 & 0.95 & & & \\
\hline
\end{tabular}

$\mathrm{K}-\mathrm{M}-\mathrm{O}$ measure of sampling adequacy $=0.814 ;$ Bartlett test of Sphericity $=928.983 ; \mathrm{p}<0.000$.

Table 2

Results of CFA and internal reliability testing \& $\mathrm{K}-\mathrm{M}-\mathrm{O}$ measure

\begin{tabular}{|c|c|c|c|c|c|c|}
\hline Factor & Mean & SD & Loading & AVE & CR & $\mathrm{C}-\alpha$ \\
\hline Factor 1: & & & & 0.522 & 0.874 & 0.844 \\
\hline Integrate performances to find the highest position among all competitors & 3.70 & 0.985 & 0.69 & & & \\
\hline Focusing on market growth and market share indicator & 3.75 & 0.974 & 0.73 & & & \\
\hline Successful in effective in the market & 3.42 & 1.051 & 0.84 & & & \\
\hline $\begin{array}{l}\text { Providing a socially complicated environment which it is difficult for } \\
\text { competitors to imitate }\end{array}$ & 3.58 & 0.930 & 0.71 & & & \\
\hline Fully committing to the society and tries to create value for that & 3.38 & 0.893 & 0.68 & & & \\
\hline $\begin{array}{l}\text { Integration and re-formulation of services and create new services faster than } \\
\text { competitors }\end{array}$ & 3.47 & 0.819 & 0.67 & & & \\
\hline Factor 2: & & & & 0.669 & 0.810 & 0.777 \\
\hline Attractive offers the customers are not superior compared to competitors & 3.27 & 1.067 & 0.66 & & & \\
\hline Providing efficient services with quality and flexibility & 3.32 & 1.104 & 0.92 & & & \\
\hline Investing in customer loyalty and satisfaction and create a positive impression & 3.03 & 1.118 & 0.85 & & & \\
\hline Factor 3: & & & & 0.61 & 0.83 & 0.953 \\
\hline Profit rate is higher than the industry average & 3.30 & 0.922 & 0.58 & & & \\
\hline Increasing the efficiency in the financial processes and save costs & 3.60 & 0.991 & 0.97 & & & \\
\hline
\end{tabular}

\section{Table 3}

Discriminant validity analysis

\begin{tabular}{lcll}
\hline Factors & EE & PC & CR \\
\hline EE & 0.742 & & \\
PC & 0.419 & 0.605 & \\
CR & 0.206 & 0.235 & 0.564 \\
\hline
\end{tabular}


Table 4

Discriminant validity analysis

\begin{tabular}{llll}
\hline Factors & SCAM & SCAC & SCAF \\
\hline SCAM & 0.522 & & \\
SCAC & 0.176 & 0.669 & 0.636 \\
SCAF & 0.250 & 0.231 & \\
\hline
\end{tabular}

Table 5

Overall fit indices of the CFA model

\begin{tabular}{lcc}
\hline Fit index & Scores & Recommended cut-off value \\
\hline Absolute fit Indices & & $\leq 3$ \\
$X^{2} /$ df & 2.84 & $\geq 0.9 ; \geq 0.8$ \\
GFI & 0.96 & $\geq 0.9 ; \geq 0.8$ \\
AGFI & 0.91 & $\geq 0.9$ \\
Comparative fit Indices & & $\geq 0.9$ \\
NFI & 0.95 & $\leq 0.08 ; \leq 0.1$ \\
CFI & 0.94 & The higher, the better \\
Parsimonious fit Indices & & The higher, the better \\
RMSEA & 0.07 & \\
PGFI & 0.92 & \\
PNFI & 0.96 &
\end{tabular}

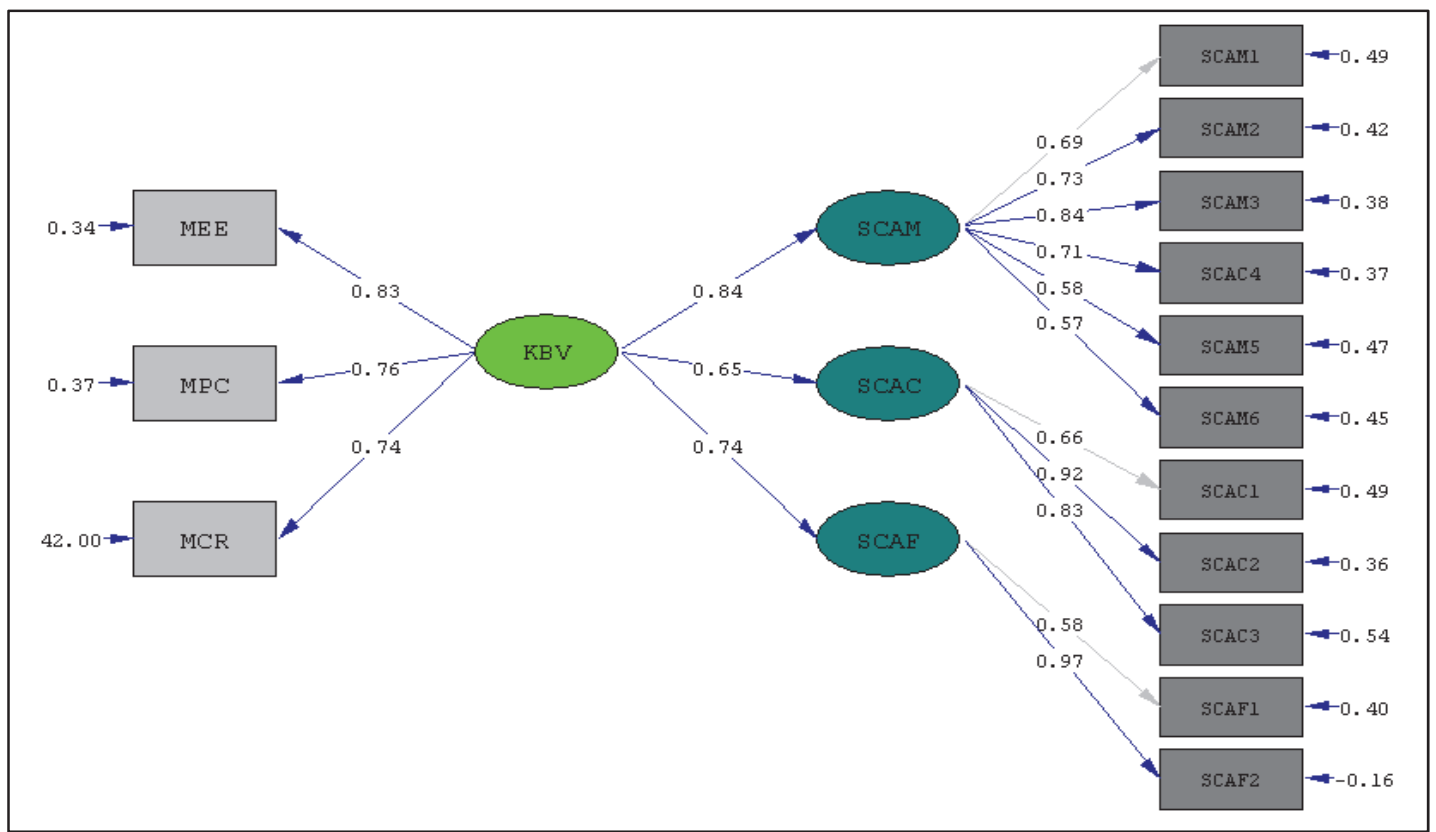

Fig. 3. Structural Relationship model between KBV and SCA

\section{Hypothesis testing}

In the hypothesis testing stage, the proposed hypotheses were examined by using the Structural Equation Modeling (SEM) technique. The findings (Table 6) for H1 (KBV to SCAM; $p<0.000$ ) implies that KBV has a positive and significant relationship with SCAM in Mellat bank. Pertaining to $\mathrm{H} 2$ (KBV to SCAC; $p<0.000$ ), the findings revealed that there is a positive relationship between the 
dimensions of KBV and SCAC. For the third hypothesis, H3 (KBV to SCAF, $\beta 21=0.53 ; \mathrm{p}<0.000$ ), the results were significant, implying that there is a significant relationship between KBV and SCAF.

Table 6

Standardized path coefficients

\begin{tabular}{cccc}
\hline Hypotheses & Estimate & $\mathrm{p}$ & Remarks \\
\hline $\mathrm{H}_{1}$ & 0.84 & $<0.000$ & Supported \\
$\mathrm{H}_{2}$ & 0.65 & $<0.000$ & Supported \\
$\mathrm{H}_{3}$ & 0.78 & $<0.000$ & Supported \\
\hline
\end{tabular}

\section{Discussion}

The findings of the current study guide the banks to a better understanding of the importance of KBV in their managerial actions in becoming a truly market, customer and financial center. Hence, it is imperative for service providers to devote more attention to embrace KBV as a vital management tool for improving competitiveness. Put it simply, in a view of the highly competitive service environment, service practitioners should emphasize on KBV as a feasible change management tool to achieve a greater degree of SCA within their banks. Consequently, banks should constantly monitor the competitive service markets and response to changes better than their rivals do. Furthermore, this study shows that the role of KBV has expanded and contributed to SCA. From the analysis, it was shown that $\mathrm{KBV}$ contributes significantly and positively to SCA. In other words, KBV implementation can improve the SCA of the Mellat bank. When KBV dimensions are present in the bank, Banks will be prompt, proper and reliable, thus enhancing the assurance of the bank's services towards the customers. Consequently, increase their profits and productivity.

\section{References}

Alrubaiee, L., \& Al-Nazer, N. (2010). Investigate the impact of relationship marketing orientation on customer loyalty: the customer's perspective. International Journal of Marketing Studies, 2(1), 155167.

Akroush M, Al-Mohammad, S. (2010). The effect of marketing knowledge management on organizational erformance: An empirical investigation of the telecommunications organizations in Jordan. International Journal of Emerging Markets, 5(1), 38-77.

Amini, A., Darani, M., Afshani, M., \& Amini, Z. (2012). Effectiveness of marketing strategies and corporate image on brand equity as a sustainable competitive advantage. Interdisciplinary Journal of Contemporary Research in Business, 4(2), 192-205.

Anderson, J.C., \& Gerbing, D.W. (1988). Structural equation modeling in practice: a review and recommended two-step approach. Psychological Bulletin, 103(3), 411-423.

Bagozzi, R.P., \& Yi, Y. (1988). On the evaluation of structural equation models. Journal of Academy of Marketing Science, 16(1), 74-94.

Barney, J.B. (2000). Firm resources and competitive advantage. Advances in Strategic Management, 17, 203- 227.

Barchan, M. (1998). Knowledge for business growth: how Celemi ensures strategic gains by measuring intangible assets. Knowledge Management Review, 3(4), 13-15.

Bhatt, G.D. (2001). Knowledge management in organizations: Examining the interaction between technologies, techniques and people. Journal of Knowledge Management, 5(1), 68-75.

Bollen, K.A. (1989). A new incremental fit index for general structural equation models. Sociological Methods and Research, 17(3), 303-316.

Burns, P. (2008). Corporate Entrepreneurship: Building the Entrepreneurial Organization, Palgrave Macmillan: New York.

Browne, M.W., \& Cudeck, R. (1992). Alternative ways of assessing model fit. Sociological Methods Research, 21(2), 230-258. 
Campbell, D.T. (1959). Convergent and discriminant validation by the multitrait-multimethod matrix. Psychological Bulletin, 56(2), 81-105.

Carlos, M. P., Sousa, E. R., \& Fernando, L. (2010). The key role of managers' values in exporting: Influence on customer responsiveness and export performance. Journal of International Marketing, $18,1-19$.

Christensen. C. M. (2001). The past and future of competitive advantage. MIT Sloan Management Review, 42,105-19.

Collinson, S. (1999). Knowledge management capabilities for steel makers: a British-Japanese corporate alliance for organizational learning. Technology Analysis \& Strategic Management, 11(3), 337-58.

Davenport, T.H., De Long, D.W., \& Beers, M.C. (1998). Successful knowledge management projects. Sloan Management Review, 39(2), 43-57.

Drucker, P.F. (1993). Managing for the future: The 1990 s and beyond, $2^{\text {nd }}$ ed. Truman Talley, New York.

Evans, M., Jamal, A., \& Foxall, G. (2009). Consumer Behavior. West Sussex, England: John Wiley \& Sons Ltd.

Fornell, C., \& Larcker, D.F. (1981). Evaluating structural equation models with unobservable variables and measurement error. Journal of Marketing Research, 18(1), 39-50.

Gupta, S., Woodside, A., Dubelaar, C., \& Bradmore, D. (2009). Diffusing knowledge-based core competencies for leveraging innovation strategies: Modeling outsourcing to knowledge process organizations (KPOs) in pharmaceutical networks. Industrial Marketing Management, 38(2), 219227.

Hamidizadeh, M.A., \& Taheri, M. (2013). A comprehensive literature review in competitive advantages of businesses. Asian Journal of Research in Marketing, 2(6), 76-97.

Holliday, C. (2001). Sustainable growth the Du Pont way. Harvard Business Review, 79(8), 129-135.

Jafari, M., \& Rezaee, F. (2014). The effect of resource based view on sustainable compatibility advantage. Management Science Letters, 4, 2537-2554.

Jang, S., Hong, K., Bock, G.W., \& Kim, I. (2002). Knowledge management and process innovation: The knowledge transformation path in Samsung SDI. Journal of Knowledge Management, 6, 479485.

Johnson, G., Scholes, K., \& Whittington, R. (2008). Exploring corporate strategy; Text and Cases, FT Prentice Hall, Pearson Education.

Kline, R.B. (2005). Principles and Practice of Structural Equation Modeling. Guilford Press, New York.

Kogut, B., \& Zander, U. (1996). What firms do? Coordination, identity, and learning. Organization Science, 7(5), 502-518.

Ljungquist, U. (2008). Specification of core competence and associated components: A proposed model and a case illustration. European Business Review, 20(1), 73-90.

Seungkwon, J., Kilpyo, H., Gee, W.B., \& Ilhwan, K. (2002). Knowledge management and process innovation: the knowledge transformation path in Samsung SDI. Journal of Knowledge Management, 6(5), 479-485.

Macintosh, A. (1998). Knowledge asset management. Available at: http://www.aiai.ed.ac.uk/ alm/kamlnks.html.

Massey, A., Montoya-Weiss, M., \& O’Driscoll, T. (2002). Knowledge management in pursuit of performance: insights from Nortel networks. MIS Quarterly, 26(3), 269-289.

Marakas, G.M. (1999). Decision support systems in the twenty-first century. Illustrated. Upper Saddle River, N.J., Prentice Hall. Pennsylvania State University.

Michailova, S., \& Husted, K. (2003). Knowledge sharing in Russian companies with western participation. Management International, 6(2), 19-28.

Michailova, S., \& Husted, K. (2003). Knowledge-sharing hostility in Russian firms. California Management Review, 45, 59-77. 
Nonaka, I., \& Takeuchi, H. (1995). The knowledge-creating company: How Japanese companies create the dynamics of innovation. USA: Oxford University Press.

Nonaka, I. (1994). A dynamic theory of organizational knowledge creation. Organization Science, 5(1), 14-37.

Nunnally, J.C., \& Bernstein, I.H. (1994). Psychometric Theory. McGraw-Hill: New York.

Prahalad, C.K., \& Hamel, G. (1990). The core competence of the corporation. Harvard Business Review, 68(3), 79-91.

Kogut, B., \& Zander, U. (1996). What firms do? Coordination, identity, and learning. Organization science, 7(5), 502-518.

Rezaee, F., \& Jafari, M. (2015). The effect of marketing knowledge management on sustainable competitive advantage: Evidence from banking industry. Accounting, 1(2), 69-88.

Oliver, RL. (2000). Whence consumer loyalty? Journal of Marketing, special issue, 63, 33-44.

Pearce, J. A., \& Robinson, R. B. (2000). Strategic management: formulation, Implementation, and Control. Irwin Mc Graw- Hill, Boston, MA.

Prahalad, C. K., \& Hamel, G. (1990). The core competence of the corporation. Harvard Business Review, 68, 79-91.

Reed, R., \& Defillippi, R. (1990). Casual ambiguity, barriers to imitation, and sustainable competitive advantage. Academy of Management Review, 15, 88-102.

Rijamampianina, R., Abratt, R., \& February, Y. (2003). A framework for concentric diversification through sustainable competitive advantage. Management Decision, 41(4), 362-371.

Rowley, J. (2005). Customer knowledge management or consumer surveillance. Global Business and Economics Review, 7(1), 100-110.

Seetharaman, A., Nadzir, Z.A.B.M., \& Gunalan, S. (2001). A conceptual study on brand valuation, Journal of Product and Brand Management, 10(4), 243-256.

Tanriverdi, H. (2005). Information technology relatedness, knowledge management capability, and performance of multi business firms. MIS Quarterly, 29(2), 311-334.

Thompson, A., \& Peteraf, M.A., Gamble, J.E., \& Strickland, A.J. (2012). Crafting and executing strategy concepts and readings. McGraw Hill Irwin: New York.

Trung, T.D.H. (2014). Obtaining sustainable competitive advantage from customer loyalty: A perspective of marketing-mix strategy and corporate social responsibility. Working paper, Department of international business administration, College of Business Chinese Culture University.

White, B.A., \& Moraschinelli, E. (2009). The Pursuit of sustainable competitive Advantage - A profile of the Starbucks Corporation. Working paper, International Business and Entrepreneurship, Malardalen University.

Zeleny, M. (2005). Knowledge-information circulation through the enterprise: forward to the roots of knowledge management. In Data Mining and Knowledge Management (pp. 22-33). Springer Berlin Heidelberg. 